\title{
Xây dựng hệ thống câu hỏi theo định hướng phát triển năng lực học sinh trong dạy học truyện ngắn Nam Cao ở trường phổ thông
}

\author{
Lê Hải Anh ${ }^{*}$ \\ Truoòng Đại học Giáo dục, ĐHQG Hà Nội, 144 Xuân Thủy, Cầu Giấy, Hà Nội, Việt Nam \\ Nhận ngày 10 tháng 2 năm 2017 \\ Chỉnh sửa ngày 13 tháng 6 năm 2017; Chấp nhận đăng ngày 15 tháng 6 năm 2017
}

Tóm tắt: Qua việc khảo sát và đánh giá hệ thống câu hỏi hướng dẫn đọc hiểu các truyện ngắn của Nam Cao trong sách giáo khoa Ngữ văn hiện hành, bài viết đề xuất hệ thống câu hỏi theo định hướng phát triển năng lực học sinh trong dạy học truyện ngắn Nam Cao ở trường phổ thông. Các câu hỏi được đề xuất vừa giúp $\mathrm{HS}$ đọc hiểu truyện của Nam Cao theo đặc trưng thể loại, vừa tuân thủ quy trình dạy học đọc hiểu.

Từ khóa: Câu hỏi, năng lực, đọc hiểu, truyện ngắn, Nam Cao.

\section{1. Đặt vấn đề}

Truyện ngắn của Nam Cao có một vị trí quan trọng trong hệ thống các văn bản được dạy học đọc hiểu trong nhà trường phổ thông, bởi đây là các tác phẩm của một tác gia lớn trong nền văn học Việt Nam hiện đại. Tuy nhiên, việc dạy học đọc hiểu các văn bản (VB) này chưa thực sự theo định hướng phát triển năng lực học sinh (HS). Một trong những nguyên nhân đưa đến hiện tượng này là do hệ thống câu hỏi trong sách giáo khoa (SGK) chưa được xây dựng một cách có hệ thống, theo một mô hình nhất định để phát triển phát triển năng lực người học. Để giúp việc dạy học truyện ngắn của Nam Cao có hiệu quả hơn, cần xây dựng hệ thống câu hỏi theo định hướng phát triển năng lực HS để giáo viên $(\mathrm{GV})$ sử dụng trong quá trình tổ chức các hoạt động đọc hiểu các văn bản này.

ĐT.: 84-913360504.

Email: lehaianh@vnu.edu.vn

https://doi.org/10.25073/2588-1159/vnuer.4080
2. Những cơ sở để xây dụng hệ thống câu hỏi theo định hướng phát triển năng lực học sinh trong dạy học truyện ngắn của Nam Cao ở trường phổ thông

2.1. Câu hỏi trong dạy học đọc hiểu văn bản theo định huớng phát triển năng lục học sinh

2.1.1. Câu hỏi trong dạy học theo định hướng phát triển năng lực học sinh

Trong giờ dạy học theo định hướng phát triển năng lực HS, GV không truyền thụ kiến thức một chiều mà phải sử dụng các phương pháp dạy học tích cực để tổ chức các hoạt động dạy học.

Để hướng dẫn và tổ chức các hoạt động dạy học trong lớp học, giáo viên thường chuẩn bị hệ thống các yêu cầu, nhiệm vụ, vấn đề để kiểm tra kiến thức và hiểu biết trước của $\mathrm{HS}$, huy động kiến thức và kinh nghiệm hiện có để tạo ra sự hiểu biết và ý nghĩa mới; giúp học sinh mở rộng suy nghĩ của mình từ những điều cụ thể và thực tế đến sự phân tích và đánh giá; thúc đẩy học sinh suy nghĩ về cách họ đã học được... nhằm 
đạt được mục tiêu của bài học. Những yêu cầu đó có thể được diễn đạt dưới dạng các câu nghi vấn (có dấu hỏi ở cuối câu) hoặc câu mệnh mệnh/câu cầu khiến - từ đây gọi chung là câu hỏi. Các câu hỏi này chính là công cụ dạy học của giáo viên.

Trong dạy học theo định hướng phát triển năng lực HS, giáo viên phải giúp HS thông qua bài học hình thành được tri thức, kĩ năng, thái độ; vận dụng những tri thức, kĩ năng, thái độ đó vào những tình huống mới. Để đạt được mục tiêu đó, $\mathrm{GV}$ có thể sử dụng các câu hỏi theo các mức độ sau đây:

- Câu hỏi ở mức độ nhận biết: trong câu hỏi thường xuất hiện các từ yêu cầu HS nêu, mô tả, nhận định, hồi tưởng...

- Câu hỏi ở mức độ thông hiểu: trong câu hỏi thường xuất hiện các từ: trình bày lại, phân tích, suy luận, giải thích, cho thấy như thế nào...

- Câu hỏi ở mức độ vận dụng: trong câu hỏi thường xuất hiện các từ: dụ đoán, đánh giá, so sánh và đối chiếu, lựa chọn... ${ }^{1}$

2.1.2. Câu hỏi trong dạy học đọc hiểu để phát triển năng lực người học

Có nhiều quan niệm về đọc hiểu văn bản. Tuy nhiên, gần đây quan niệm của PISA về đọc hiểu được nhiều người tán thành hơn cả. Theo PISA, "Đọc hiểu là sự hiểu biết, sư dụng, phản hồi và chiếm lĩnh các văn bản viết nhằm đạt được nhũng muc đích, phát triển tri thức và tiềm năng cũng nhu tham gia vào đời sống $x \tilde{a}$ hội của mối cá nhân" [1].

Tiến trình đọc hiểu gồm 3 giai đoạn: trước khi đoc, trong khi đọc, sau khi đọc. Nhìn chung, ở mỗi giai đoạn, người đọc chủ yếu thực hiện các hoạt động sau:

* Trước khi đọc:

- Huy động những hiểu biết về tác giả, văn bản;

- Dựa vào nhan đề, đề tài của tác phẩm để dự đoán về nội dung của văn bản;

- Đọc lướt để cảm nhận chung về nội dung của văn bản.

* Trong khi đọc: giải thích, cắt nghĩa, phân loại, so sánh, kết nối... thông tin (theo đặc

\footnotetext{
$\overline{{ }^{1} \text { Dựa theo }}$

http://oer.educ.cam.ac.uk/wiki/Teaching_Approaches/Que stioning
}

trưng của văn bản) để tạo nên hiểu biết chung về văn bản.

* Sau khi đọc, người đọc:

- Đánh giá về hình thức và nội dung của văn bản;

- Vận dụng những hiểu biết về văn bản đã đọc vào việc đọc các văn bản mới;

- Giải quyết các nhiệm vụ khác nhau trong học tập và đời sống bằng việc sử dụng những hiểu biết về văn bản đã đọc.

Trong nhà trường phổ thông, HS được dạy học đọc hiểu hai loại văn bản, đó là văn bản văn học và văn bản nhật dụng. Văn bản văn học là những văn bản được viết theo các thể loại của văn học như tự sự, trữ tình, kịch, nghị luận. Khi dạy học đọc hiểu văn bản văn học, $\mathrm{GV}$ phải hướng dẫn HS đọc hiểu theo đặc trưng thể loại để hình thành và phát triển năng giao tiếp và năng lực tiếp nhận văn học.

Trong dạy học đọc hiểu văn bản văn học, câu hỏi được sử dụng để hướng dẫn, tổ chức các hoạt động đọc hiểu của HS; giúp HS hiểu được nghệ thuật, nội dung, ý nghĩa của văn bản, đồng thời vận dụng những điều đã học được vào thực tế đời sống (đọc văn bản mới có cùng đề tài, chủ đề; tạo lập văn bản trong đó có sử dụng những tri thức đã đọc hiểu; điều chỉnh thái độ, quan điểm sống của bản thân...).

Để đạt được mục tiêu đó, các câu hỏi trong dạy học đọc hiểu văn bản văn học của GV phải đáp ứng những yêu cầu sau đây:

- Câu hỏi đọc hiểu VB phải được thiết kế phù hợp với đặc trưng thể loại của VB.

- Câu hỏi đọc hiểu VB, đặc biệt là VB văn học, phải hướng dẫn người đọc khám phá, tìm hiểu cả về phương diện nội dung lẫn hình thức nghệ thuật của VB.

- Câu hỏi đọc hiểu VB phải phản ánh đúng các hoạt động tư duy và xảm xúc xảy ra trong tiến trình đọc $\mathrm{VB}$, chẳng hạn như liên hệ; hình dung, tưởng tượng; dự đoán; suy luận; khái quát hóa; đánh giá; kiểm soát quá trình đọc, v.v...

- Câu hỏi đọc hiểu VB phải được thiết kế đảm bảo các giai đoạn của tiến trình đọc hiểu" [2]. 


\section{2. Đặc điểm truyện ngắn của Nam Cao}

\subsection{1. Đặc điểm của truyện ngắn}

"Truyện ngắn là một thể loại văn học. Nó thường là các câu chuyện kể bằng văn xuôi và có xu hướng ngắn gọn, súc tích và hàm nghĩa hơn các câu chuyện dài như tiểu thuyết. Thông thường truyện ngắn có độ dài chỉ từ vài dòng đến vài chục trang... Vì thế, tình huống truyện luôn là vấn đề quan trọng bậc nhất của nghệ thuật truyện ngắn.

Truyện ngắn thường chỉ tập trung vào một tình huống, một chủ đề nhất định... Do đó, truyện ngắn thường hết sức hạn chế về nhân vật, thời gian và không gian trong truyện ngắn cũng không trải dài như tiểu thuyết. Đôi khi truyện ngắn chỉ là một khoảnh khắc của cuộc sống...

Paul Bourget, nhà văn và nhà phê bình Pháp thế kỷ 20 có nhận định: "Phong cách của truyện ngắn và của tiểu thuyết rất khác nhau. Phong cách của truyện ngắn là thuộc về tình tiết...". ${ }^{2}$

Như vậy, khi đọc hiểu truyện ngắn, cần khai thác được các yếu tố: cốt truyện, tình huống truyện, nhân vật, tình tiết/chi tiết của truyện.

2.2.2. Nghệ thuật viết truyện của Nam Cao

Truyện của Nam Cao có những đặc điểm sau đây:

“- Nam Cao có tài đặc biệt trong việc phân tích và diễn tả tâm lí nhân vật. Ngòi bút của ông có thể thâm nhập vào những quá trình tâm lí phức tạp, những ngõ ngách sâu kín nhất của tâm hồn con người; từ đó, dựng lên được những nhân vật - tư tưởng vừa có tầm khái quát lớn vừa có cá tính độc đáo. Theo dòng cảm nghĩ của nhân vật, mạch tự sự của tác phẩm Nam Cao thường đảo lộn trật tự tự nhiên của thời gian, không gian, tạo nên lối kết cấu vừa linh hoạt vừa hết sức chặt chẽ. Cũng vì am hiểu tâm lí nhân vật mà Nam Cao đã tạo được nhiều đoạn đối thoại và độc thoại nội tâm rất chân thật, sinh động.

- Một nét hấp dẫn khác của truyện Nam Cao là tính triết lí sâu sắc, triết lí mà không khô khan, xuất phát từ cuộc sống thực và từ tâm tư

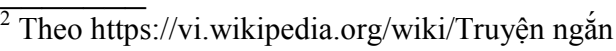

đầy đau đớn dằn vặt của nhà văn. Đọc truyện Nam Cao, không nên chỉ chú ý tới đề tài hay nội dung xã hội trực tiếp của tác phẩm mà còn phải căn cứ vào những tư tưởng của ông phát biểu qua hình tượng và những mệnh đề triết lí ông rút ra từ thực tế.

- Truyện Nam Cao luôn thay đổi giọng điệu, trong đó có hai giọng cơ bản nhất: giọng tự sự lạnh lùng với những đại từ nhân xưng có sắc thái dửng dưng hay khinh bạc: $\mathrm{y}$, thị, hắn,... và giọng trữ tình sôi nổi tha thiết, thường mở đầu bằng những thán từ như "chao ôi", "hỡi ôi”, ... Hai giọng văn đối lập nhau cứ chuyển hóa qua lại, tạo nên những trang viết thú vị, lôi cuốn. Ngoài ra là giọng điệu khác nhau của các nhân vật được trần thuật bằng lời kể trực tiếp hay nửa trực tiếp" [3].

Như vậy, dạy học đọc hiểu truyện ngắn của Nam Cao không thể không làm rõ nghệ thuật viết truyện của ông.

Ngoài ra, khi dạy học đọc hiểu truyện ngắn của Nam Cao, cần làm nồi bật được tư tưởng của nhà văn: “... dù viết về đề tài nào, truyện Nam Cao cũng thường thể hiện tư tưởng chung: nỗi băn khoăn đến đau đớn trước tình trạng con người bị hủy hoại về nhân phẩm do cuộc sống đói nghèo đẩy tới”’’

\subsection{Thực trang câu hỏi huớng dẫn đọc hiểu} truyện ngắn của Nam Cao trong sách giáo khoa Ngữ văn hiện hành

Đối chiếu với những yêu cầu đã nêu ở trên về câu hỏi trong dạy học đọc hiểu văn bản và đặc điểm nghệ thuật truyện ngắn của Nam Cao, có thể thấy, các câu hỏi trong SGK Ngữ văn hiện hành chưa thực sự giúp HS đọc hiểu được truyện ngắn của Nam Cao theo định hướng phát triển năng lực người học [4]. Hầu như không có câu hỏi vận dụng những kiến thức, kĩ năng đã đọc vào thực tiễn đời sống của học sinh để giải quyết các tình huống cụ thể. Đặc biệt, các câu hỏi chưa được thiết kế theo một mô hình nhất định và không đảm bảo các giai đoạn của tiến trình đọc hiểu. Ngoài ra, các câu hỏi chưa tạo ra mối liên hệ giữa việc đọc hiểu các văn bản

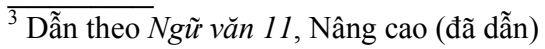


trước (ở Lớp 8) với những văn bản sau (ở Lớp 11) đề thấy được phong cách nghệ thuật của Nam Cao; thường hỏi nội dung trước, nghệ thuật sau (ngược lại với nguyên tắc đi từ nghệ thuật đến nội dung trong đọc hiểu văn bản văn học)...

Chẳng hạn, với truyện Lão Hạc, SGK Ngũ văn 8 , Tập một đưa ra những câu hỏi để hướng dẫn HS đọc hiểu văn bản như sau [5]:

(1) Phân tích diễn biến tâm trạng của lão Hạc xung quanh việc bán chó. Qua đó, em thấy lão Hạc là người như thế nào?

(2) Em hiểu như thế nào về nguyên nhân cái chết của lão Hạc? Qua những điều lão Hạc thu xếp nhờ cậy "ồng giáo" rồi sau đó tìm đến cái chết, em suy nghĩ gì về tình cảnh và tính cách của lão?

(3) Em thấy thái độ, tình cảm của nhân vật "tôi" đối với lão Hạc như thế nào?

(4) Khi nghe Binh Tư cho biết lão Hạc xin hắn bả chó để bắt một con chó hàng xóm thì nhân vật "tôi” cảm thấy "cuộc đời quả thật... đáng buồn", nhưng khi chứng kiến cái chết đau đớn của lão Hạc, "tôi" lại nghĩ: "Không! Cuộc đời chưa hẳn đã đáng buồn, hay vẫn đáng buồn nhưng lại đáng buồn theo một nghĩa khác”. Em hiểu ý nghĩ đó của nhân vật "tôi” như thế nào?

(5) Theo em, cái hay của truyện thể hiện rõ nhất ở những điểm nào? Việc tạo dựng tình huống truyện bất ngờ có tác dụng như thể nào? Cách xây dựng nhân vật có gì đặc sắc? Việc truyện được kể bằng lời của nhân vật "tôi" (ngôi thứ nhất) có hiệu quả nghệ thuật gì?

$\left(6^{*}\right)$ Em hiểu thế nào về ý nghĩ của nhân vật "tôi" (có thể coi là tác giả) qua đoạn văn sau: "Chao ôi! Đối với... che lấp mất".

(7*) Qua đoạn trích Túc nuoóc võ bò và truyện ngắn Lão $H a ̣ c$, em hiểu gì về cuộc sống và phẩm chất của người nông dân trong xã hội cũ?

Còn với truyện Chí Phèo (trích), SGK Ngũ văn 11, Tập một nêu các câu hỏi sau [6]:

- Truyện Chí Phèo (trích):

(1) Tóm tắt đoạn trích; nêu ý chính của từng đoạn đã được đánh số.

(2) Hãy nêu ý nghĩa chi tiết tiếng chửi của nhân vật Chí Phèo.
(3) Các mối quan hệ bá Kiến - Chí Phèo và thị Nở - Chí Phèo trong truyện ngắn có ý nghĩa gì trong việc thể hiện số phân, tính cách của nhân vật Chí Phèo?

(4) Nêu những diễn biến tâm trạng của Chí Phèo sau khi gặp thị Nở. Vì sao khi bị thị Nở dứt tình, Chí Phèo lại xách dao đi giết Bá Kiến và tự sát? $\mathrm{Bi}$ kịch lớn nhất của Chí Phèo được thể hiện trong truyện là gì?

(5) Ngôn ngữ kể chuyện và ngôn ngữ nhân vật trong truyện ngắn này có những điểm gì đặc sắc? (Chú ý lời trần thuật nửa trực tiếp ở đoạn mở đầu (đoạn 1); độc thoại nội tâm của Chí Phèo sau cơn tỉnh rượu (đoạn 3); những lời đối thoại giữa Chí Phèo với thị Nở (đoạn 4 ) và nhất là với bá Kiến ở gần cuối truyện (đoạn 5).

(6) Nêu nhận xét khái quát về nội dung và nghệ thuật của truyện ngắn Chí Phèo.

(7) Bài tập nâng cao: Phân tích và làm nổi bật tính điển hình của nhân vật Chí Phèo hoặc bá Kiến.

Như vậy, cần phải xây dựng hệ thống câu hỏi để tổ chức các hoạt động đọc hiểu truyện ngắn của Nam Cao theo định hướng phát triển năng lực $\mathrm{HS}$, đồng thời, hiểu được truyện ngắn của Nam Cao theo đặc trưng thể loại và phong cách nghệ thuật của nhà văn.

\section{3. Đề xuất câu hỏi sử dụng trong dạy học đọc hiểu truyện ngắn của Nam Cao theo định hướng phát triển năng lực người học}

\subsection{Mô hình câu hỏi trong dạy học đọc hiểu truyện ngắn của Nam Cao theo định huớng phát triển năng lục}

Hệ thống câu hỏi trong dạy học đọc hiểu truyện ngắn của Nam Cao (ở THCS và THPT) cần được biên soạn theo một mô hình nhất định. Mô hình đó được thiết kế theo tiến trình đọc hiểu và đặc điểm nghệ thuật viết truyện của nhà văn. Đây là những câu hỏi cốt lõi cần sử dụng trong dạy học đọc hiểu truyện ngắn của Nam Cao. Với những tác phẩm cụ thể, tùy theo năng lực của $\mathrm{HS}, \mathrm{GV}$ có thể đưa thêm những câu hỏi khác cho phù hợp. 


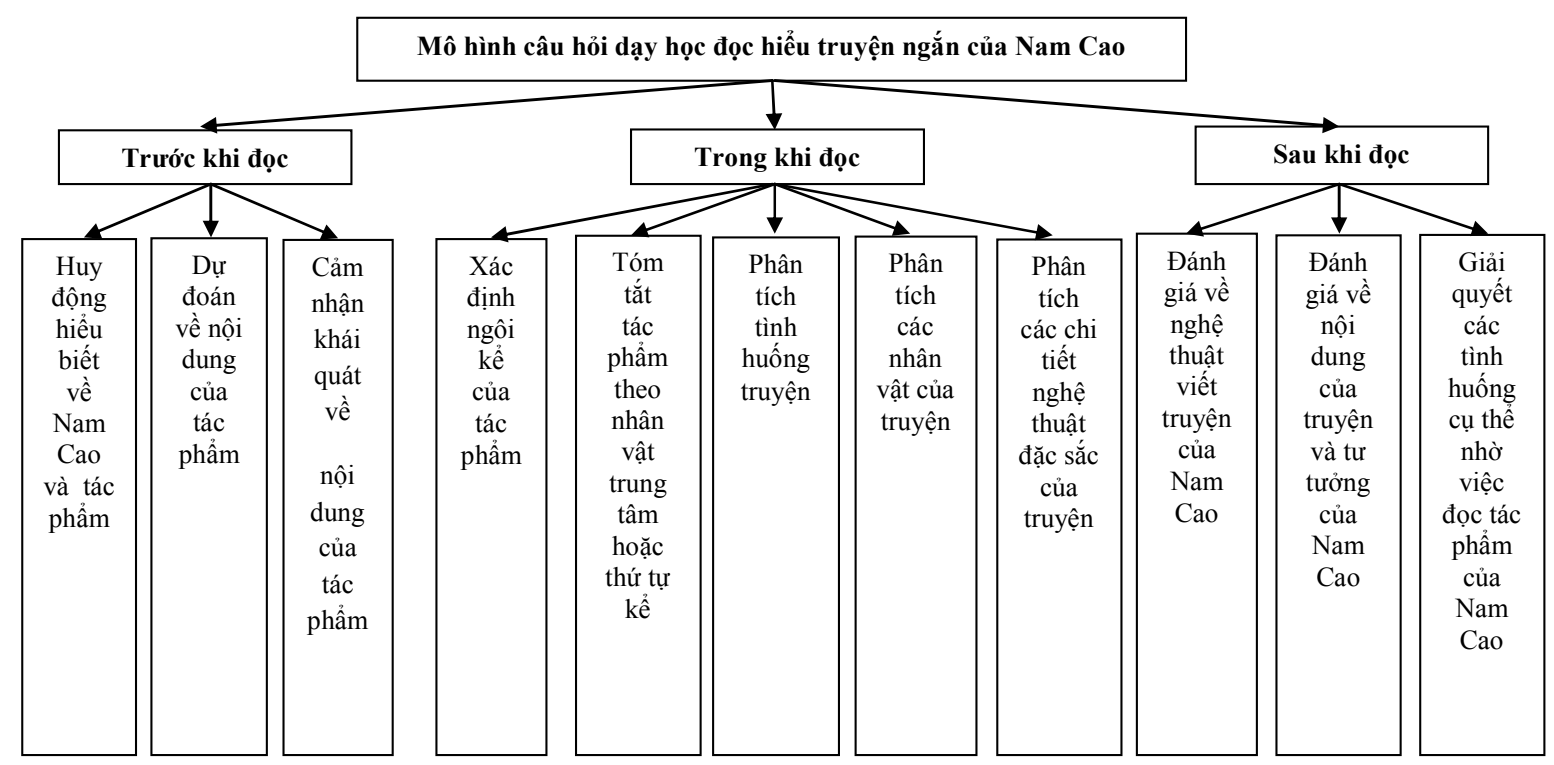

3.2. Hệ thống câu hỏi trong dạy học đọc hiểu môt số truyện ngắn của Nam Cao cho hoc sinh phổ thông theo định hướng phát triển năng lực

Dựa vào mô hình đã đề xuất ở trên, GV sẽ xây dựng hệ thống câu hỏi cốt lõi và các câu hỏi cụ thể phù hợp với từng truyện ngắn của Nam Cao được dạy học ở THCS và THPT.

Dưới đây là hệ thống câu hỏi được đề xuất cho hai truyện Lão Hạc và Chí Phèo bao gồm một số câu hỏi của SGK hiện hành, một số câu hỏi của SGK đã được điều chỉnh và một số câu hỏi được biên soạn mới.

3.2.1. Với truyện "Lão Hạc"

a) Trước khi đọc

(1) Hãy chia sẻ những điều em biết về người nông dân trước Cách mạng tháng Tám năm 1945.

(2) Hãy kể tên một số tác phẩm văn học viết về người nông dân trước Cách mạng tháng Tám năm 1945. Trong số các tác phẩm đó, em thích tác phẩm nào nhất? Vì sao?

(3) Hãy nêu một vài nét mà em biết về tác giả Nam Cao. Em ấn tượng nhất điều gì về tác giả và những tác phẩm của ông?

(4) Truyện ngắn có tên là "Lão Hạc". Đọc nhan đề của truyện ngắn, em thử dự đoán về nội dung của câu chuyện.
(5) Đọc lướt tác phẩm và cho biết điều em dự đoán về nội dung của câu chuyện đúng hay sai? Nếu sai, hãy chỉ ra sự khác nhau giữa dự đoán của em và câu chuyện mà tác giả kể.

b) Trong khi đọc

(1) Truyện được kể ở ngôi thứ mấy? Tác dụng của việc sử dụng ngôi kể đó là gì?

(2) Em nhận xét như thế nào về giọng điệu của người kể chuyện trong tác phẩm?

(3) Tóm tắt ngắn gọn truyện ngắn Lão Hạc.

(4) Hãy nêu những sự việc chính xảy ra đối với Lão Hạc? Theo em, sự việc nào là quan trọng nhất để đưa đến kết thúc của truyện? Vì sao?

(5) Việc lão Hạc bán con chó Vàng là một tình huống quan trọng trong truyện. Vì sao lão Hạc phải bán chó? Hãy phân tích diễn biến tâm trạng của lão Hạc xung quanh việc bán chó. Qua đó, em thấy lão Hạc là người như thế nào?

(6) Em hiểu như thế nào về nguyên nhân cái chết của lão Hạc? Qua những điều lão Hạc thu xếp nhờ cậy "ông giáo" rồi sau đó tìm đến cái chết, em suy nghĩ gì về tình cảnh và tính cách của lão?

(7) Trong truyện, nhân vật "tôi" (có thể là tác giả) đã có những lời nói, cử chỉ, thái độ như thế nào đối với lão Hạc? Em nghĩ như thể nào về nhân vật này? 
(8) Khi nghe Binh Tư cho biết lão Hạc xin hắn bả chó để bắt một con chó hàng xóm thì nhân vật "tôi” cảm thấy "cuộc đời quả thật... đáng buồn", nhưng khi chứng kiến cái chết đau đớn của lão Hạc, "tôi" lại nghĩ: "Không! Cuộc đời chưa hẳn đã đáng buồn, hay vẫn đáng buồn nhưng lại đáng buồn theo một nghĩa khác". Em hiểu ý nghĩ đó của nhân vật "tôi" như thế nào?

(9) Em hiểu thế nào về ý nghĩ của nhân vật "tôi" (có thể coi là tác giả) qua đoạn văn sau: "Chao ôi! Đối với... che lấp mất".

(10) Hãy khái quát nghệ thuật xây dựng nhân vật lão Hạc trong truyện.

c) Sau khi đọc

(1) Qua đoạn trích Tức nước vớ bờ và truyện ngắn $L a \tilde{o} o H a c$, em có thêm những hiểu biết gì về cuộc sống và phẩm chất của người nông dân trong xã hội cũ?

(2) Em thấy cách kể chuyện của Nam Cao có gì khác so với Ngô Tất Tố trong đoạn trích Tức nước võ bờ?

(3) Cho tình huống sau: Mấy năm sau khi lão Hạc chết, anh con trai của lão trở về. Nếu là nhân vật "tôi", em sẽ nói gì với con trai của lão Hạc?

(4) Em rút ra bài học gì về cách nhìn nhận, đánh giá con người sau khi đọc truyện Lão Hac?

\subsubsection{Với truyện "Chí Phèo"}

a) Trước khi đọc

(1) Truyện Chí Phèo viết cùng đề tài với tác phẩm nào đã học của Nam Cao? Nhắc lại một vài nét tiêu biểu về nội dung và nghệ thuật của tác phẩm đó?

(2) Truyện có tên là "Chí Phèo". Đó là tên của nhân vật chính trong truyện. Cái tên đó gợi cho em những suy nghĩ gì? Hãy nêu dự đoán của em về nội dung của truyện.

(3) Tìm và nêu vài nét khái quát về hoàn cảnh sáng tác của tác phẩm.

(4) Đọc lướt tác phẩm và cho biết: theo em, mục đích của tác giả khi viết tác phẩm này là gì?

(5) Em đã đọc nhiều truyện ngắn. Theo em, những yếu tố nào của truyện ngắn cần khai thác trong quá trình đọc truyện?

b) Trong khi đọc
(1) Truyện được kể ở ngôi thứ mấy?

(2) Tóm tắt đoạn trích; nêu ý chính của từng đoạn đã được đánh số.

(3) Ngôn ngữ kể chuyện và ngôn ngữ nhân vật trong truyện ngắn này có những điểm gì đặc sắc? (Chú ý lời trần thuật nửa trực tiếp ở đoạn mở đầu (đoạn 1); độc thoại nội tâm của Chí Phèo sau cơn tỉnh rượu (đoạn 3 ); những lời đối thoại giữa Chí Phèo với thị Nở (đoạn 4 ) và nhất là với bá Kiến ở gần cuối truyện (đoạn 5)).

(4) Tóm tắt những sự việc chính xảy ra đối với nhân vật Chí Phèo trong đoạn trích. Theo em, sự việc nào là quan trọng nhất để đưa đến kết thúc của truyện? Vì sao?

(5) Hãy nêu ý nghĩa chi tiết tiếng chửi của nhân vật Chí Phèo trong đoạn trích.

(6) Nêu những diễn biến tâm trạng của Chí Phèo sau khi gặp thị Nở. Tác giả đã sử dụng những hình thức ngôn ngữ nào để diễn tả tâm trạng đó của nhân vật?

(7) Liệt kê những chi tiết liên quan đến sự quan tâm, chăm sóc của thị Nở đối với Chí Phèo. Sự quan tâm, chăm sóc ấy đã làm thay đổi con người Chí Phèo như thế nào? Em đánh giá gì về nhân vật thị Nở?

(8) Vì sao khi bị thị Nở dứt tình, Chí Phèo lại xách dao đi giết Bá Kiến và tự sát? Em đánh giá như thế nào về hành động giết bá Kiến và tự sát của Chí Phèo?

(9) Theo em, bi kịch lớn nhất của Chí Phèo được thể hiện trong truyện là gì? Thể hiện bi kịch đó, nhà văn muốn gửi đến người đọc thông điệp nào?

c) Sau khi đọc

(1) Em hãy đánh giá về nội dung và nghệ thuật của truyện ngắn Chí Phèo.

(2) Đoạn trích giúp em hiểu thêm những gì về cuộc sống và phẩm chất của người nông dân trong xã hội cũ?

(3) Em thấy cách viết của Nam Cao trong truyện Chí Phèo có gì khác với truyện Lão Hạc đã học?

(4) Nếu được viết một kết thúc khác cho truyện Chí Phèo, em sẽ viết như thế nào?

(5) Tình cảm nào của nhà văn Nam Cao dành cho người nông dân trong tác phẩm khiến em cảm động nhất? Vì sao? 


\section{Kết luận}

Trong thời điểm hiện nay, để dạy học đọc hiểu truyện ngắn của Nam Cao nói riêng, dạy học đọc hiểu văn bản văn học nói chung, GV cần rà soát lại hệ thống câu hỏi trong SGK Ngữ văn hiện hành, đánh giá các câu hỏi đó, điều chỉnh và biên soạn thêm các câu hỏi mới theo một mô hình nhất định, phù hợp với thể loại của văn bản để tổ chức hoạt động đọc hiểu, nhằm giúp cho việc dạy học đọc hiểu văn bản phát triển được năng lực của học sinh.

\section{Tài liệu tham khảo}

[1] Viện Khoa học giáo dục Việt Nam, Nhóm nghiên cứu (2008), Chương trình đánh giá học sinh quốc tế (PISA) và vấn đề tham gia của Việt Nam, Tạp chí KHGD, số 29.

[2] Nguyễn Thị Ngọc Thúy, Đề xuất hệ thống câu hỏi dạy học đọc hiểu văn bản tự sự theo định hướng phát triển năng lực, Tạp chí Khoa học Trường Đại học Sư phạm Thành phố Hồ Chí Minh, Tập 14 (4b)/2017.

[3] Dẫn theo Ngũu văn 11, Nâng cao, Tập một, NXB Giáo dục Việt Nam.

[4] Bộ Giáo dục và Đào tạo, Chương trình Giáo dục phổ thông môn Ngữ văn, NXB Giáo dục, 2006.

[5] Bộ Giáo dục và Đào tạo, Ngữ văn 8 , Tập một, NXB Giáo dục Việt Nam, 2016.

[6] Bộ Giáo dục và Đào tạo, Ngữ văn 11 Nâng cao, Tập một, NXB Giáo dục Việt Nam, 2016.

\title{
Building a Competence-based Question System for Teaching Nam Cao's Short Stories in School
}

\author{
Le Hai Anh \\ VNU University of Education, 144 Xuan Thuy, Cau Giay, Hanoi, Vietnam
}

\begin{abstract}
By examining and evaluating the questions system that guides Nam Cao short stories reading comprehension in the current Vietnamese language an Literature textbook, the paper proposes a question system based on a competence-oriented approach to teaching Nam Cao's short stories in school. The suggested questions, while adhering to the reading comprehension teaching procedure, do assist the students in reading the stories by Nam Cao according to the genre characteristics.
\end{abstract}

Keywords: Questions, competence, reading comprehension, short story, Nam Cao. 